\title{
Reseñas de libros
}

La revista Universitas Psychologica abre una nueva sección destinada a la "Reseña de Libros" e invita a enviar textos alusivos y pertinentes que contengan la referencia del libro respectivo bajo normas APA, al igual que un resumen analítico que refiera las tesis, hipótesis, unidades de análisis, debates y discusiones conclusivas de los mismos, que vayan mucho más allá de una descripción narrativa. El Editor de la sesión de libros es el Profesor Hugo Escobar Melo quien recibirá los materiales para su análisis, aprobación y publicación. Pueden dirigirse a escobarh@javeriana.edu.co

\section{Book reviews}

Universitas Psychologica will feature a new section for book reviews. We will accept relevant texts containing an APA-formatted reference of the book, and an analytical review that includes the main ideas, hypotheses, units of analysis, debates and discussions going beyond a mere description. The section editor is professor Hugo Escobar Melo, who will receive the materials for analysis, approval and publication. Please send reviews to escobarh@javeriana.edu.co. 
Social Construction and Health: An interview with Sheila McNamee

Construcción Social y Salud: Una entrevista con Sheila McNamee

Laura Vilela e Souza ${ }^{1}$, Manoel Antônio dos Santos $^{2}$, Clarissa Mendonça Corradi-Webster ${ }^{3}$, Carla Guanaes ${ }^{4}$, Murilo dos Santos Moscheta ${ }^{5}$, Universidade de São Paulo, Ribeirão Preto, Brasil

Sheila McNamee is an important author in the social constructionist movement. The social constructionist orientation focuses in the processes by which people construct meaning and value. As a metatheory, this orientation assumes that meaning is created in what people do together. Thus, what we take to be reality is produced in the moment-tomoment interactions of people in relationships. In this sense, social construction can be understood as a philosophical orientation that challenges the conventional and traditional forms of understanding, knowledge, science and human relations (Gergen, 1985).

McNamee is Professor of Communication at the University of New Hampshire, Durham, New Hampshire, USA. She is founder and Board Member of the Taos Institute, a non-profit organization that promotes constructionist ideas, writings, publications and practices (http://www.taosinstitute. net). Working with transformative dialogue in different contexts (including psychotherapy, organizations, communities, education and health care), McNamee is the author of important books in the field, such as Relational Responsibility: Resour-

1 Faculdade de Filosofia, Ciências e Letras de Ribeirão Preto da Universidade de São Paulo. E-mail: lacake@uol.com.br

2 Departamento de Psicologia e Educação da Faculdade de Filosofia, Ciências e Letras de Ribeirão Preto da Universidade de São Paulo. Bolsista de Produtividade em Pesquisa do CNPq. E-mail: masantos@ffclrp.usp.br

3 Departamento de Enfermagem Psiquiátrica e Ciências Humanas da Escola de Enfermagem de Ribeirão Preto da Universidade de São Paulo.E-mail: clarissac@usp.br

4 Departamento de Psicologia e Educação da Faculdade de Filosofia, Ciências e Letras de Ribeirão Preto da Universidade de São Paulo. E-mail: carlaguanaes@ffclrp.usp.br

5 Faculdade de Filosofia, Ciências e Letras de Ribeirão Preto da Universidade de São Paulo.E-mail: moscheta2@hotmail.com ces for Sustainable Dialogue (McNamee \& Gergen, 1999), Therapy as Social Construction (McNamee \& Gergen, 1992), Philosophy in Therapy: The Social Poetics of Therapeutic Conversation (McNamee \& Deissler, 2000) and The Social Construction of Organization (Hosking \& McNamee, 2006). She has also published numerous articles and chapters on social constructionism. She lectures and consults in a variety of international contexts.

In March 2009, Sheila came to Brazil as a visiting professor in the Department of Psychology and Education at the Faculty of Philosophy, Sciences and Languages of Ribeirão Preto at the University of São Paulo (Ribeirão Preto - São Paulo - Brazil) and gave us this interview. The relationship between a social constructionist sensibility and health care was the focus of our conversation. This interview explores social constructionism as an important source for the creation of alternative health care practices.

Interviewer: You are considered an important author in the social constructionist movement. How do you describe your professional trajectory?

McNamee: How much time do we have? (laughs). Well, when I went to the university for the first time, I studied philosophy. I don't know why, it just really intrigued me then and it still does. For a variety of reasons, I left the university after two years - mostly as a rebellious act to claim my independence - and during the next two years I worked as a secretary. It didn't take very long before I realized I wanted to return to school. When I returned to my studies, I decided that I wanted to study communication, but for all the wrong reasons. At that time, I thought it would be very interesting to go into advertising of all things. I arrived at the university to study communication and had the opportunity to work in the Department of Communication. I requested a research position. I remember the departmental secretary looked at me and said, "Are you crazy? No students want to do research!" I guess I was crazy because the idea of being involved in faculty research really excited me. That was when I met Barnett Pearce who became a very influential person in my life. I 
became the departmental research assistant and he was responsible for pairing me up with various faculty in need of assistance. He took me under his wing. Barnett's background is deeply philosophical. So, there was just this absolutely natural fit. It wasn't a week or two weeks before he was inviting me to sit in on the graduate seminars and special research group that would meet once a week at lunch time to read and talk about Wittgenstein and other philosophers, and their implication for communication theory. From there, it just continued. I never had an idea that I would become a professor. I never had an idea to become an academic, a scholar. I just was curious and kept studying, becoming more and more immersed in a broader philosophical orientation. This orientation is central to an understanding of human communication - what people do together. I feel very lucky that my home discipline has been communication and not psychology, because I think in psychology is very hard to find your way around to constructionism. So, that's the short story.

Interviewer: And when was the first time you met social constructionism?

McNamee: Well, I was lucky to be involved with Barnett Pearce and Vernon Cronen who, at that time, were developing a theory called The Coordinated Management of Meaning theory (or CMM for short). Vernon became my Ph.D. advisor and Barnett was on my committee. I would say that this theory was my first introduction to social construction - although we were not using that term at the time. I first met social construction, as a term, in about 1979 or 1980 when I read Bergen and Luckman's (1966), The Social Construction of Reality. At about the same time, I was introduced to Ken Gergen's work and then had the privilege of meeting him for the first time in 1980 . So we have known each other for a very long time.

Interviewer: So, now we are going to talk about social construtionism nowadays. What do you think are the biggest challenges, the fields that promise and future perspectives?

McNamee: Let me set a context here. I think social construction is radically different today than it was in nineteen eighty, when I was beginning to find my way there. Originally - because constructionism was such a different way of talking about social interaction and the world - it was just as dogmatic as positivism, for example. Of course, we can say that now with great "hindsight." At the time, Gergen and others were trying to make compelling arguments for an alternative understanding of social life (see Gergen's seminal book, Toward Transformation in Social Knowledge). I remember in those early days trying desperate to prove to people that we make meaning in relationships. In fact, the group that I was working with in my graduate studies, actually came up with ways to measure the process of meaning-making. On one hand, we could say that relationally we were being responsive to the audience we needed to address. We needed to address the audience of other academics, of other scholars, for whom the language of science -- the language of truth - was the only language spoken or heard. So, we had an early phase of really trying to prove the case, prove the point, of social construction. I think we have come - thankfully - to a really wonderful place now, where it is not about proving anything. And it is not about saying that individualism, modernism, positivism, empiricism is wrong or bad. It is simply about exposing different ways of being in the world. Neither is ultimately right or wrong. However, adopting one philosophical stance produces certain sorts of outcomes, and adopting another, produces other kinds of outcomes. Most important is that we realize that we can make these choices. Now, I think, the most exiting move in constructionism is a move away from the dogma of academic scholarly writing to prove a point, toward an opening up of the conversation to include people beyond the academy, such as health care providers or people working in the field, who might come and listen to a lecture and not feel excluded from it. The hope is that everyone could feel that they were getting ideas for their practice. I think that is what is exciting. It is exciting to look at social construction as a practical theory, a theory in action, not as some abstract set of assumptions that help us make arguments. In terms of disciplines that are using constructionism now and where things are 
pushing forward, I'm not sure I could say it is any one, specific discipline. There is a lot of interest in health care and the ways in which social constructionist practices might be transformative. I know that my own experience with health care is limited so perhaps I see it this way because of the people with whom I am related -- like all of you. These ideas in various forms have been a central aspect of psychotherapy - particularly family therapy. This is one domain where real innovation and movement away from traditional understandings of social life has always been present. The earlier the systemic ideas were a departure from the standard way of thinking about psychotherapy. Basically, where the true innovations have taken place has been in fields that are connected with practice, as opposed to fields that are purely academic.

Interviewer: Considering that this is your fifth time here in Brazil, tell us the story of your connection to the country.

McNamee: It's a great story. In 2001 I was sitting in my office and an e-mail message popped into my inbox. It was from Carla Guanaes and Emerson F. Rasera, unknown to me, introducing themselves and saying that they wanted to come and study with me in the United States. I have had many other foreigners come, so I'm used to that sort of request. I asked them a few questions about themselves and their work and then I said "Sure, if you want to come, by all means come." They, as you well know, were just wonderful people to work with -- smart and interesting -- and it was a very meaningful time. They stayed for several months which was wonderful. From their initial contact, all of this has unfolded. The collaboration between me and USP students and faculty that has developed over the years is also a strong statement about relational forms of being and ways in which relationships open up possibilities. The next possibility for collaboration was from Carla and Emerson's advisor, Marisa Japur, who invited me to come to USP to teach a graduate seminar in social construction. As part of that seminar, I met people from Familiae, who invited me to do something with them, and then the group in São Paulo and on and on it goes. My last visit (befo- re this one) was in 2007 as a Visiting Professor in the Nursing School. This visit was arranged by Silvana Mishima, Celiane Camargo-Borges, Carla Guanaes, and Emerson Rasera. And this current visit was arranged by Manoel Antônio dos Santos, advisor of Laura Vilela e Souza and Murilo S. Moscheta. Each time I visit Brazil, I meet wonderful students - many of whom have come to work with me in New Hampshire, including Celiane Camargo-Borges, Laura Vilela e Souza, Clarissa Mendonça Corradi-Webster, and Murilo S. Moscheta. Am I leaving anyone out? It has been a back and forth that, for me, is very exciting. We have been able to generate some very exciting and innovative ideas and work with people who really care about the ideas and are eager to talk about them. So the history in Brazil is a very strong one and a really wonderful one. I love the way that it goes both ways. It's nice to have people come visit me, instead of always bringing me here (although I love coming to Brazil!), to let you bring the ideas and practices back to your own culture and be the spokepersons.

Interviewer: From this relationship with our country, how do you see social constructionism nowadays in Brazil?

McNamee: I think we just have to look at what happened this week to see an incredible change from the first time I visited Brazil. For my first visit, there was a nice big class -- probably thirty or so people. But I do remember also during that period giving a public lecture to a very small group. I don't think anyone really knew what social construction was and so not many people attended the lecture. There just did not seem to be interest in or knowledge about social construction within the University community at that time. Marisa and her students in psychology were ahead of the rest. Yet, yesterday and today, in the two public lectures I gave on campus, there was such enormous interest and attentiveness. I kept asking myself, "How can people listen for so long to a lecture in English that is being translated?" It takes a lot of effort. I think that this speaks volumes about how interested, curious, and supportive this community is. And it just keeps growing and getting bigger and bigger and 
bigger. I think that all of you do a wonderful job in spreading the ideas by working as you do. You see how it is contagious. People watch how you work and ask, "You can really do that? You can work that way? Tell me more about it." So, I imagine it will just keep growing and growing here. It is nice.

Interviewer In the next questions we are going to talk more about health. How was your involvement with research and intervention in the context of health?

McNamee: My involvement is not a direct involvement in the sense that this is a domain where I do my research. It is one of many areas in which I work. Having said that, my background has been very much in mental health, looking at therapeutic process, beginning with my doctoral studies. I wrote my Ph.D. dissertation on therapeutic process and I continued from there exploring therapy as social construction (see Therapy as Social Construction, 1992) I have been trained as a family therapist and I have worked as a family therapist. That area in health is something that it is familiar to me, but not as familiar as someone who has trained through all of their education in, for example, Psychology. I do not have that background, and I am grateful for that. I am really grateful for having a background in communication theory and an appreciation for the complexity of what is happening when we communicate. Over time, I started having more connection with health centers where mental health was a part of the overall services offered along with all aspects of health care I had the opportunity to work, for example, on end of life communication with an oncologist. I have also done some writing and public lectures on that topic. But I would say that the deepest connection to issues of public health have been here, at USP, with all of you and particularly with Celiane Camargo-Borges and Silvana Mishima. A year and a half ago when I was here for five weeks as a visitant professor in the Nursing School was a wonderful opportunity. I had the chance to work not only with students who were interested in public health and studying to became doctors and nurses, but had the opportunity to work with a lot of community health centers, doing some consulting for them. I had the opportunity to visit some of the poor communities and even the favela to have a sense of the public health needs in the community. I think that my deepest connection with health is through the community in Ribeirao Preto, but certainly it is supported by a trajectory of involvement over many years that I have had with mental health and with other health related issues.

Interviewer: The most popular definition of health is the "state of complete physical, mental and social well-being, and not merely the absence of disease". How do you position yourself towards this definition?

McNamee: I do agree with that. I think you cannot treat a physical problem and assume that someone will have good health because of that. The social environments that we live in, the relational aspects of our lives, all contribute to our well-being in many ways, physically, emotionally, etc. I think that treating the whole person in his or her context is the best model. I was thinking the other day that we now have all this technology available. Particularly in health care, the belief seems to be that technology will provide better care. My only feeling is that technology is fine, but if you learn how to use the technology, that is not enough. You need to learn how to collaborate with your colleagues and with patients around that technology. I think that with this technological push, particularly in health care, we are in a really dangerous moment right now, where what is happening in medical schools, for example, is teaching people to use the technology more than teaching people how to relate with patients. And that frightens me. I know that Obama has an idea that it is the whole system that needs to be examined, not just technology and health care. We have to look at how we educate doctors and health professionals. I think that is a really important definition of health, and if we hold on to that, then perhaps we will be developing educational programs for health professionals that do not forget that very important piece of dealing with patients. Also, we must deal with colleagues, in an interdisciplinary manner, breaking down the silos. Working in transdisciplinary teams becomes more and more important. If students are educated in health care, in a way that does not presume that doctors are superiors 
to nurses and so forth, and if we introduce new ways of understanding what it means to be a doctor that is not a hierarchical understanding, then we will promote much more effective, collaborative team work among health care providers. Again, it is probably because I am an academic -- education is my life -- but I think the central place for radical change is education. What I like about what I see here at USP is so much work from the university going out into the community to educate health professionals working in the neighborhoods rather than always making the community come to the university. I think that it is important.

Interviewer You already gave some ideas, but could you tell us a little bit more about the contributions that you think social constructionism can give towards the challenges that we confront nowadays in the health care practices?

McNamee: Sure, to me it is just so obvious that the impulse, the move to more collaborative, participatory, open forms of practice - which are very much featured by a constructionist orientation - can only help health care and public health. I love to reference Celiane's dissertation research (Camargo-Borges, Mishima \& McNamee, 2006) where she worked with a group that was a successful group because of the way that they fully participated. It was a group meeting about hypertension, but they fully participated in making suggestions of the important topics they needed to discuss. The health care professionals who would meet with this group were not dogmatically setting the agenda, but where very open to talk about whatever this group wanted to talk about. So if they wanted to talk about home remedies, for example, talking about home remedies was ok. They would invite a pharmacist to talk with them about homeopathic cures, instead of saying: "Oh, no! Home remedies do not work. They are not the real thing. You need to use the real medicine." So when you look at this example, the question becomes, "how do we create those kind of opportunities where people can participate, where they feel invited in, where they want to be present?" I think we need to engage in a cultural change where professionals somehow are able to give the message to users (clients) that their voices are important. And perhaps if we can achieve this, clients also might come to realize that their voices are important. It is going to take a lot of work, because, for so long, we have operated under the assumption that professionals are all-knowing. Professionals will solve our problems and the best stance for the patient is to remain mute. The patient is not important. The patient's job is simply to describe his or her symptoms. Not everybody is like that, of course. But we need a radical reorientation and it is not just with health care professionals. It needs to start with normal, ordinary everyday people who feel that they can see their health care professional as a partner, a partner in maintaining their own well-being. I think constructionist ideas and form of practice can help us in that way. I personally feel that constructionism helps us forget about what we are "supposed" to know as professionals and allows us to be fully present in the moment. We can be more humane, more genuine in the moment with other people. And so, if that message, if this way of operating, if social constructionist practices could be infused into health care, I think we could have a radical change.

Interviewer: One of the most useful concepts that you created is the idea of relational responsibility. In which way do you think that this concept can be helpful in the health care context?

McNamee: The development of that notion of relational responsibility goes back to the earlier point I made where, in the earlier days of social construction, we were dogmatically arguing the point that this was the better perspective. The critique of social construction always came from a very naive understanding, claiming it was immoral, unethical and irresponsible. This is because, of course, in the naïve understanding of social construction, people understand that if you do not like something, you just construct it differently. But that is not what is being argued by constructionists. We are not free to construct the world any which way we want. I genuinely got so frustrated with continuing confronting this naïve critique -- trying to make an argument for the ethics of, for the morality of, for the responsible position of social construction 
- that the idea emerged in my teaching. For the constructionist, to be responsible is to be responsible to the process of relating itself. So, instead of being responsible for things, or for people, we are responsible for keeping the conversation going, and for keeping the conversation going in a way that might generate something useful for our going on together. I like this idea. I think it is very important.

Interviewer Sheila, nowadays, all the science, and all the changes in health, we are discussing a lot about prevention, based a lot on risk factors, to prevent diseases and to increase the life expectance of the population, and based on the prevention discourse, we started to organize a lot of educational practices in health, telling people what they should do, what kind of things they should avoid. We would like to ask you to talk a little bit more about that. How does social constructionism understands the discourse of prevention?

McNamee: My initial response is that the discourse of prevention is really coherent with constructionism because is very close to the discourse of possibility, the discourse of appreciation. How can we take the best of what we do, the best health practices, and move them forward? Ok, so I think it is a really nice fit. At the same time, let me draw an analogy, a connection between the discourse of prevention that is really dominant in the health care field, everywhere, and the discourse of sustainability that is everywhere. When most people hear or enter into the discourse of sustainability, there is a real pushback because people think that it means they need to give something up -- give up having things, give up using the lights all the time, give up taking a shower every day. I think, in some ways, that the discourse of prevention is also heard in some venues this way. Instead of being proactive and remind people that they can take care of themselves, that they have good health habits, we say, "No, do not eat that hamburger, have an apple instead." And it seems like you are giving up what you want. So, I think the discourse of prevention, itself, content free, is really coherent with constructionism. I think we have to be careful how we crack this discourse in terms of the behaviors. So, is it about giving up or is it about gaining? In some way, if we think about Appreciative Inquiry and taking the best of what you have done and moving it forward and how energizing that is, I think we have fallen short with the discourse of prevention. We give the message, "Let's be healthy and develop healthy attitudes and behaviors," but it means you cannot do a lot of stuff that you are doing. Maybe we need to drop the "don't do behavior" and push forward to a "can do" stance. I think a lot of health care professionals do take that stance, but the public at large only hears about it in terms of not being able to eat the foods they want, not being able to sit in front of the T.V. all day long, etc, etc. So, maybe just a slant in the other direction would be helpful.

Interviewer We would like you to talk about power relationships in the health care context.

McNamee: To the constructionist, power is a relationship. It is not an entity that can be traded, passed back and forth, or "given" to someone. It is not a part of someone, like a heart or a liver is. Power is not in the message or in a person. The implications of thinking and talking this way are important to note. If a doctor is viewed as a powerful person, it is not because he or she has power. Rather, a doctor's power is created in the momentby-moment interaction s/he has with others. A power relationship is a constructed relationship.

Interviewer What kind of person does preventative actions in health construct? Working with nursing students, we have to deal with that all the time. They are one of the professional groups that have the biggest responsibility to engage in these educational practices. They tell people what they should or should not do, which behaviors they have to change, etc. The students learn about the risk factors and which things cause each disease. When they work with a family's orientation, they get very frustrated and very nervous and they come to us asking what they could do because they understand that the person has to do something different in order to be healthy. How does social constructionism discuss these issues?

McNamee: This takes us back to what we were talking about a little while ago, the centrality of education. This is what I would imagine. Students come in to the Nursing School where a priority is placed on relating with patients rather than 
on the techniques or science they must learn in order to cure illness. This would alter their idea of what it means to be a successful professional In another words, the tradition of learning how to diagnose, treat, and cure is not that the focus of attention. Understandably, this is knowledge that they need to know, but more important than any of that knowledge is understanding that change happens in very small ways and in our moment to moment interactions with others. In other words, change is organic. It happens in very local places and in visceral ways. If this were the first thing students learned, then their training would be more about understanding how important it is to be with people, to be responsive to people. It is much more about communication than it is about the knowledge that they also need to have. I would not want an artist working on my car engine, necessarily. To work on the engine of a car you need to know the parts and how things work. But, which would you rather have, a mechanic who is a master and can explain to you what is happening with your car and says that you have to take a better care of your car, etc; or a mechanic who expects when your car falls apart, you will bring it to him so he can fix it? I would rather have the first one who can help me prevent my car from falling apart in the middle of a highway on a dark night. We have became a culture that trains professionals in technique, without any sense of what having knowledge of those techniques is supposed to do in terms of helping humanity, or in terms of changing the world. It really would be a reorientation, and this is not just about health care. This is the case in every profession. Instead of training people in technique, let's pay more attention to talking about what it means to work with people. For example, in the domain of education, I could be a great professor and know my stuff and in fact I would say in the early part of my career I taught social construction saying "Here are the five things you need to know!" and then I gave a test and they did not get it because I was not really teaching it, I was teaching it as dogma, not as a way of being in the world, and inviting people into that.
Interviewer What do you think about the discourse of empowerment and autonomy? Do you think that they represent a new advance to our traditional health practice?

McNamee: It depends on how you define empowerment and autonomy. I understand that, in the context of the health care, one of the goals is to empower people to be in charge of themselves. I think this is ok, but at the same time let's not go too far with that. What is wrong with being dependent on one another? And in fact, I would probably want to problematize those notions a little bit, because think of the ways in which the notions or expectations about autonomy and empowerment can be particularly pathologizing, particularly in health care. Let's just talk about autonomy for now, as one of the main features. To the extent that my child, let's say, has some kind of disability, he might not be considered autonomous. He is dependent upon me; he has a problem. The more I think about all the things he can not do on his own and the more the health professionals support my attempts to "help him," the more we all engage in pathologizing discourse. It is an endless cycle or, as Ken Gergen calls it, a "cycle of progressive infirmity."

If we return to the constructionist idea that we all need each other in order to make meaning, then why do we see dependence upon one another as a flaw? Could we hold the tension between the two? I am not saying we should throw out the idea of autonomy or throw out the idea of empowerment. But could we avoid this oversimplification and, instead, accept that complexity? Yes, we want people to feel like they can take care of themselves, but we also want people to recognize that when they need others to help them care for themselves, this is not a problem. We have swum so deeply into the discourses of empowerment and autonomy, saying, "We have got to help the person, the individual," that we don't even realize that, in the process, we have ripped them apart from family, friends, and community. If the family has the idea that the individual is not autonomous -is perhaps ill or unable to care for him/herself- they remove the person and put him or her in an institution where $\mathrm{s} /$ he has a hundred percent care. It is a twisted way 
of thinking because we value self care instead of relational care. And to the extent that the person who is pathologized does not change, s/he is a "resistant" patient. So, now we have a new label. Not only you are an alcoholic, but you are a resistant alcoholic. You not only have eating disorders, but you are a resistant patient with an eating disorder.

Interviewer: We want to talk a little bit about evaluation in the health care context. If nowadays we do not take cure as the only way to measure success in a treatment, how can a professional evaluate the process or the success of his work?

McNamee: One of the interesting things about evaluation is we always save it to the end, and I think from a constructionist stands that valuation (as I like to call it instead of evaluation) is an ongoing process. Whose standards are we using when we evaluate? If we do not start a conversation with, for example, a patient about what would count as success, what would count as good treatment, as a good outcome, if we do not have this conversation to begin with, then we are using our own standards, and the patients -- the people we work with -- may have very different standards. I think of people who I have met in my life, who I am always worried about, because they seem to not have a lot of friends, and live alone, and do not seem very happy. And then I always have to say, "But my standards are not that person's standards." That person may be perfectly happy in his or her life. There are differences between us. Working with people, we can ask the question, "How would you know when you have become in control of your problem, when things are better, when you are cured?" This is a conversation we should be having from the very beginning of our relationship, not at the end. We can ask, "How will you know you are better? What kind of things won't you be doing anymore? What kind of things will you be doing?"

It is impossible for us to step outside of evaluation, for a variety of reasons. One is because we live in language and the minute we speak, we evaluate. When I say, "It is a nice day!" that is an evaluation. We are always distinguishing this from that, drawing lines when we speak. So we cannot step out of evaluation in that way. And also we live in a world where it is not the case that anything goes. We do not want to say this routine, this technique, this procedure is just as good as that one, that one and that one. We do need to have ways of making sense and of setting standards. But, of course, those ways of making sense are always rooted in a community, in a culture. For example, several years ago I heard a fascinating story about a community in the U.S. where an indigenous culture had, for some reason, settled. A little community had popped up in the middle of a typical, American community. One American family was living next door to an indigenous family. There had been a lot of conflict between the two families and between the two cultures. The American, in the midst of one argument, had cursed the foreigners, and said some horrible things. Among the horrible things said was a wish that the head of the indigenous family would die. This man had been acculturated enough into American ways of living while still holding dearly onto his own cultural practices. With this mix of cultural resources, he responded to the death threat of his neighbor by going to the emergency room at the local hospital. His belief - his indigenous belief - led him to understand that if someone curses you, you have a devil inside you, and you need to go through a ritual to expel the devil. Yet he also understood that, in American culture, when there is something wrong with the body, you go to the emergency room of the hospital. So, that is what he did. But his request to the emergency health professionals was a request to rid his body of the devil. Instead of laughing at him, the doctors listened to the story and gave the man a little pill that did nothing more than turning his urine red. The doctor told the man, "You will see now that you will get rid of the devil, when you urinate." He $\mathrm{did}$, and his threat of death was resolved. We could say that western medical science has the truth, but there are also other forms of practice that are true for people and work for people. Homeopathic and holistic health care work in many cultures. We want to have a way to evaluate, but we do not, at the same time, want to say that our standards are more important than other standards. Again, it is similar to the issue of autonomy. There is that 
tension where we want standards but we do not want absolute standards that allow no diversity, because we do live in a diverse world.

Carvalho: Some studies have pointed out that, in the health field, there are a lot of medical processes. How can diagnosis be part of the process of care and investigation, and how can it be understood from the social constructionist approach?

McNamee: It is a great question and the example of Jaakko Seikkula's dialogical form of diagnosis comes to mind. Again, just as in the question about evaluation, we live in a moment in time where we have many tools for diagnosis. People want to know what is wrong, not everybody, but most. They want to know what they should be doing to take care of themselves. The question emerges, do we leave diagnosis to one person or do we create more inclusive environments for diagnosis? Even if we are talking about something, like cancer, that often we can say either it is there or it is not, there are family members and others who are close to the person with cancer who have so much more information. So, regardless of whether cancer is there or not there, what have family and close friends noticed about the way this person has been operating, feeling, if they have been sleeping a lot. There are so many things that often a person him or herself might not be aware of. And more important, once a diagnosis of cancer is given, it is the people closest to the patient who really can share with medical professionals what is happening. They are the ones who can report how the diagnosis is affecting the patient. And, this is important because the way in which someone approaches the diagnosis, the way someone understands it, has tremendous impact on how they make meaning of themselves and their illness. It helps a person make decisions about whether surgery is the best form of treatment or not. We know that there is a connection between how we are feeling in our relational life and how well or poorly we endure medical treatment. These are not issues that we should take lightly. I think that the biggest challenge we have is to broaden the domain of participation in health care. How can we expand inclusiveness in well-being. While there may be health care professionals who think that they know better than anybody, I think the reluctance concerning more participatory and inclusive forms of health care is an issue of time and money. It is really about economics and efficiency. We can think of the green (sustainability) movement. We cannot keep increasing the cost of health care. We use the phrase, "Time is money" and if I am a doctor, I have less and less time to spend with you because I have to get on to the next person. I need to see a high volume of patients in order to pay for the very expensive equipment that we need to do the tests. So, we need to find a way -- and I wish I had the answer, I do not -- to appreciate and privilege, to put a priority on time and relationships. I think that efficiency in many ways equals slowing down our processes of interaction. Yet, we have this correlation of efficiency and speed. Until we push aside that notion of efficiency and push aside the financial aspect that it is all about cost and money, I think we are just going to be like the mouse on the wheel in a cage - we will just keep going round and round.

Interviewer: In the eighties you contributed with work about burnout syndrome (Fruggeri $\mathbb{E} \mathrm{McN}$ amee, 1991). Nowadays which diagnose do you think should be deconstructed?

McNamee: Oh, pick anyone (laughs). You know, the work on burnout really emerged because, as you imply in your question, that was just such a huge theme, particularly among health care providers. Everybody is burned out. This is why my colleague, Laura Fruggeri, and I decided to deconstruct this phenomenon. We wanted to deconstruct what that means. Today, if I think about it, the first thing that comes to mind that would benefit from a similar study is ADD and ADHD. Everybody is ADD or ADHD. It started with children and it is now blossoming into adults. What is wrong in this complex world where we are bombarded with information? When I was young there was not a lot to do, expect to go outside and play. Of course that offered a lot to, but now there is so much, and yet we have not changed our expectations, for example, for children in the classroom. They are supposed to sit, pay attention to one person talking - the teacher. So, if the circumstances of our lives 
have changed, we need to change our institutional practices as well to meet that. And also, why is not ADD or ADHD a form of competence, being able to do many things, and be creative, and think outside of the box? There are lots of ways to talk about these issues; we should not be too quick to let one discursive construction dominant. We need to ask the question: Who gains and who loses by talking this way and not that way? I do want to say that there are people for whom a diagnosis of ADD or ADHD is very useful. They like knowing, having a term that legitimately explains their behavior. They like the idea of taking medications so they can alter their behavior to "fit in." My mission is not for or against diagnosis; it is not to take it for granted. For some people, a diagnosis is a new lease on life, a new way forward. For others, it is the kiss of death. And we cannot know. This is why we have to pay attention to the people with whom we are working.

Interviewer You have being contributing a lot about the reflections and the articulation between social constructionism and the Brazilian public health system. How do you understand that this discussion can contribute for the reflections to understand the transformation of the health system in the United States?

McNamee: That is a great question because I have been so delighted with every occasion that I have had in the United States to talk about my work in Brazil. Last year, for example, I was giving a public lecture at the University about my work in Brazil and somebody in the audience stood up and said, "Thank you! It is about time that North Americans realize that they have something to learn with South America!" I agree. I love being able to bring that message. The audiences I have spoken to have been so impressed with the work that is going on here. I know that the work that I am seeing here is not the work that is happening in the entire country. But unless we all work to lift this example up and show it, talk about it, show how it actually works and the differences it can make, then nothing is going to change. Even in these little ways, these innovative ideas are spreading. It think Americans have a lot to learn. I know that people who I have spoken with have taken a lot from the stories of work here that I have been able to share. And it is not to say that there are not sympathetic and common forms of practice happening in the US. There are other health care practices that have some similarities. So, I think we have a long way to go, but I think we are on a great road. Just keep moving. It is, I think, important for Brazilian to know the significance of the work that has been done here.

Interviewer: How does social constructionism understand nowadays worries about the body and beauty and the desire to be young forever?

McNamee: Are you asking me this personally or a social constructionist? (Laughs). It is a classic argument about media constructions and so forth. And I do not mean to imply that the media cause us to be consumed with ideas of beauty and body image. It is not a causal relationship, from my point of view, at all. But these shifting ideas of beauty are just like shifting ideas of anything else. Shifting ideas of childhood, shifting ideas of what it means to be a mother. Now, in some places to be a mother who stays at home is to be incompetent, children need to know that a mother can work, that she can be a professional. We need to remember that any discourse will shift. We have, for example, shifting ideas of sexuality. At what age should a person be a sexual being? That ranges culture to culture. So, it is unfortunate - personally, because I am getting older - to think that being young and beautiful is the way to be. But I realize that this is not the only discourse available. There are ample resources to talk about beauty and body size, and so forth. It is the case that the media do a lot to propel and promote the "thin, young forever" discourse. I do not know what to say about that except that maybe people need to just pay attention to what communities they participate in, instead of feeling less than. If you are always paying attention to the media images, then of course you are going to feel less than, because your body is not air-brushed. But if you take as your significant communities people, people who you like relating with regardless of what their bodies look like, then maybe there is a little more hope. 
Berger, P. L., \& Luckmann, T. (1966). The social construction of reality: A treatise in the sociology of knowledge. Garden City: Doubleday.

Camargo-Borges, C., Mishima, S., \& McNamee, S. (2006). Da autonomia à responsabilidade relacional: Explorando novas inteligibilidades para as práticas de saúde. Gerais: Revista Interinstitucional de Psicologia, 1 (1), 8-19.

Fruggeri, L., \& McNamee, S. (1991). Burnout as social process: A research study. In L. Fruggeri, U. Telfner, A. Castelluci, M. Marzari, M. Matteini (Eds.), A systemic model for changing mental health service delivery (pp. 1-16). London: Draper Campbell Publishers.

Gergen, K. J. (1985). The social constructionist movement in modern psychology. American Psychologist, 40, 266-275.

Gergen, K. J. (1994). Toward transformation in social knowledge (2nd ed.). Thousand Oaks: Sage.

McNamee, S., \& Gergen, K. (1992). Therapy as social construction. Thousand Oaks: Sage.

McNamee, S., \& Gergen, K. (1999). Relational responsibility: Resources for sustainable dialogue. Thousand Oaks: Sage.

McNamee, S., \& Deissler, K. (2000). Philosophy in therapy: The social poetics of therapeutic conversation. Heildelberg: Carl Auer Systeme Verlag.

Hosking, D. M., \& McNamee, S. (2006). The social construction of organization. Sweden: Liber \& Copenhagen Business School Press. 